Burkhard Berger · Alexandra Lindinger •

Harald Niederstätter •

Petra Grubwieser • Walther Parson

\title{
Y-STR typing of an Austrian population sample using a 17-locus multiplex PCR assay
}

Received: 18 May 2005 / Accepted: 5 July 2005 / Published online: 8 October 2005

(C) Springer-Verlag 2005

In Table 1 of the publication by Beger et al. [1], incorrect assignments of some $\mathrm{Y}$-single nucleotide polymorphism (SNP) haplogroups (hgs) have been identified. In particular, assignments of all but one sample belonging to hg $\mathrm{R} 1 \mathrm{~b}$ as well as some of those belonging to hgs Rlal and E3b were incorrect. A revised version of Table 1 is available as electronic supplementary material to this manuscript. The errors only affect the structure of our sample as far as the hg affiliation is concerned; the $\mathrm{Y}$-short tandem repeat data presented in this table as well as the conclusions drawn on the Y-filer multiplex are not affected. The authors want to point out that these corrected Y-SNP data are also valid for the hgs listed in Table 3 of Niederstätter et al. [2] as the same set of samples was analysed. Again, the main conclusions drawn in the latter publication are not affected. The authors would like to thank colleagues for notifying the problem and regret any inconvenience caused.

Electronic Supplementary Material Supplementary material is available for this article at http://dx.doi.org/10.1007/s00414-0050035-0 and accessible for authorized users.

The online version of the original article can be found at http://dx.doi.org/10.1007/s00414-005-0546-8.

B. Berger · A. Lindinger $\cdot$ H. Niederstätter .

P. Grubwieser · W. Parson $(\bowtie)$

Institute of Legal Medicine,

Innsbruck Medical University,

Müllerstraße 44,

6020 Innsbruck, Austria

e-mail: walther.parson@uibk.ac.at

Tel.: +43-512-5073303

Fax: $+43-512-5072764$

\section{References}

1. Berger B, Lindinger A, Niederstätter $\mathrm{H}$ et al (2005) Y-STR typing of an Austrian population sample using a 17-locus multiplex PCR assay. Int J Legal Med. DOI 10.1007/s00414005-0546-8

2. Niederstätter H, Berger B, Oberacher H et al (2004) Separate analysis of DYS385a and b versus conventional DYS385 typing: is there forensic relevance? Int J Legal Med 119:1-9 